\title{
Gifts, Drug Samples, and other Items Given to Medical Specialists by Pharmaceutical Companies
}

\author{
Paul M. McNeill • Ian H. Kerridge • Catherine Arciuli • David A. Henry • \\ Graham J. Macdonald • Richard O. Day • Suzanne R. Hill
}

Received: 28 October 2005 / Accepted: 6 June 2006/Published online: 15 November 2006

(C) Springer Science + Business Media B.V. 2006

\begin{abstract}
Aim To ascertain the quantity and nature of gifts and items provided by the pharmaceutical industry in Australia to medical specialists and to consider whether these are appropriate in terms of justifiable ethical standards, empirical research and views expressed in the literature.
\end{abstract}

Competing Interest Graham Macdonald is employed by Merck Sharp \& Dohme (Australia). Richard Day serves as an Advisory Board member for Merck Sharp \& Dohme (Australia) (rofecoxib, etoricoxib), Merck Sharp \& Dohme (Asia) (rofecoxib), Abbott Australia (adalimumab), Schering-Plough Australia (infliximab), Amgen Australia (anakinra), GlaxoSmithKline Consumer Australia (paracetamol) and, previously, Pfizer Australia (celecoxib). Any honoraria for these activities are placed in audited trust funds of St Vincent's Hospital, Sydney, to be used to support academic activities within the Department of Clinical Pharmacology.

\section{P. M. McNeill $(\square)$}

School of Public Health and Community Medicine, University of New South Wales,

Sydney, NSW 2052, Australia

e-mail: paul.mcneill@unsw.edu.au

\section{H. Kerridge}

Centre for Values Ethics and the Law in Medicine,

University of Sydney, Sydney, Australia

\section{Arciuli}

Department of Psychology,

University of Sydney, Sydney, Australia
Design and Setting Fifty-one medical Sydney specialists were asked to collect all gifts, offers, invitations, and items received from pharmaceutical companies in an eight-week period.

Main Outcome Measures The items received were categorised as promotional/educational, drug samples, clinical practice aids, office gifts, personal gifts, and invitations; and were analysed in relation to the pharmaceutical industry Code of Conduct.

Results A large number (mean=42/participant) and wide range of gifts and items were received. These included promotional/educational items $($ mean=21), drug samples $($ mean $=8)$, office gifts $($ mean $=5)$ and personal gifts $($ mean $=1)$, clinical aids $($ mean $=3)$, and invitations $($ mean $=3)$ to meals, meetings, and conferences. Most gifts and items complied with the Code with a few breaches including offers of entertainment (sporting event and cabaret), items of high monetary value (in competitions with prizes unrelated to

\footnotetext{
D. A. Henry $\cdot$ S. R. Hill

Discipline of Clinical Pharmacology,

School of Medicine and Public Health,

University of Newcastle, Callaghan,

New South Wales, Australia

G. J. Macdonald

Merck Sharp \& Dohme, South Granville, Australia

R. O. Day

Department of Physiology \& Pharmacology,

School of Medical Sciences, Faculty of Medicine,

University of New South Wales, Sydney, Australia
} 
medicine), unbranded gifts, and promotional documents presented as journal articles.

Conclusions Medical specialists received many gifts and items from pharmaceutical companies and a few that infringed the Code current at the time of the study. The findings were considered in the light of changes that have since been made to the industry Code of Conduct and professional medical guidelines on ethical relationships between physicians and the industry. In large measure, these changes are supported although some suggestions are made for stricter standards.

Keywords Code of Conduct · Gifts .

Medical specialists

\section{Introduction}

This was a study of gifts and other items received by medical specialists from pharmaceutical companies. It was conducted in Sydney, Australia, and was based on medical specialists as they are regarded by the industry as opinion leaders and have an extensive role in industry-sponsored education of junior doctors and general practitioners $[22,25]$. The study is a part of a larger project that aims to establish whether the relationship between the pharmaceutical industry, the medical profession, and medical practitioners is appropriate in terms of justifiable ethical standards, empirical research and social perspectives. A number of reports arising from the project have been published to date $[6,10,11,13,17]$.

\section{Background}

Pharmaceutical companies give gifts to doctors as a part of promoting and marketing their products [14]. There are concerns about the effect of these gifts however. Although many doctors deny the potential for gifts to influence their judgment [12, 30], it has been found that medical practitioners' attitudes to the pharmaceutical industry, their knowledge about pharmaceutical products, and prescribing behaviour are influenced by industry promotion and gift-giving $[3-5,7,8,12,21$, 29-31]. Katz et al. claim that all gifts, both large and small, create a social obligation to respond and the only way for a medical practi-tioner to reciprocate is to support the company's products [12].
Nevertheless, gifts, offers, and promotional items, remain significant elements in the relationship between the pharmaceutical industry and the medical profession [3, 21, 23-25]. These include items for the office (pens and pads), promotional items, drug samples and information, personal gifts, invitations to various events, and travel support and accommodation to attend national and international conferences and other meetings.

Australian codes and ethical guidelines, relevant to medical practitioners receiving gifts, items and other support from pharmaceutical companies, are contained in the Australian Medical Association (AMA) guidelines [26], the Royal Australasian College of Physician's (RACP) Guidelines [28], and the industry Code of Conduct [20]. Of these, the Medicines Australia (pharmaceutical industry) Code [20] and the RACP Guidelines [28] are the most important and both have been recently updated. This study was conducted in 2002 when a previous industry Code of Conduct [1] and the earlier RACP Guidelines [27] were in effect and these earlier standards are considered in this paper in relation to what was acceptable at the time.

The general principles embodied in the Code [20] and Guidelines [26, 28] are that any gift or benefit from a pharmaceutical company should leave a physician's judgment "unimpaired" [28]; that gifts that could influence prescribing of drugs should not be accepted [26]; and physicians should avoid any appearance of impropriety in accepting gifts [26, 28]. Gifts, items and other support should only be accepted if they are relevant to the practice of medicine and of benefit to patients [28]. The Medicines Australia Code limits gifts to brand-name reminders of token value [20] whereas the recently amended RACP Guidelines recommend rejecting all gifts including 'items of trivial value such as pens or message pads' and state that 'service-oriented items' are only acceptable on 'rare occasions' such as where they 'are not otherwise readily available' [28].

The industry Code, and the AMA and RACP Guidelines allow food and refreshment in association with educational meetings, conferences, or company events provided it is not lavish [28] or extravagant [20], and secondary to the educational purpose of the meeting $[26,28]$. The industry Code allows Companies to provide financial assistance to doctors to attend meetings [20] although the RACP Guidelines recommend that support should only be offered to speakers and chairpersons and that any support be distributed by 
the organisers of meetings not directly by companies [28]. Entertainment in association with professional meetings is no longer acceptable within the Medicines Australia Code [20] and is discouraged by the RACP Guidelines [28] and gifts of tickets to entertainment events are no longer acceptable [20,28].

Both the recent Code and the RACP Guidelines take a more restrictive stance on company representatives supplying drug samples to doctors. The new Medicines Australia Code requires that any drug samples only be supplied where there is a written and signed request from a health professional [20]. The RACP Guidelines state that a 'sample or a free supply of a drug' is a 'marketing exercise' in most circumstances and that accepting drug samples 'is usually inappropriate' [28]. They also recommend that doctors exercise caution in dealing with pharmaceutical company representatives and promotional materials as contact with them 'erodes physicians' ability to identify wrong claims, increases non-rational prescribing and results in acceptance of commercial rather than scientific views.' The Guidelines recommend critical evaluation of all promotional material because it is 'often biased, incomplete or unsupported by evidence and may promote unapproved uses' [28].

\section{Aim of the Study}

As a part of the broader goal of the project, in determining whether the relationship between the pharmaceutical industry and medical practitioners is appropriate, we wanted to know what doctors are actually given by pharmaceutical companies. Most studies are based on surveys and self-report, mainly in the USA. There have been few observational studies of gifts and items actually received by doctors - an exception being a study of items carried in doctors' pockets [24]. The aim of this study was to determine the number of gifts actually received by doctors within a set period. To do this we sought to ascertain all gifts, offers, invitations, and items received by 51 medical specialists in the Sydney region from pharmaceutical companies in an eight-week period at the end of 2002.

\section{Materials and Methods}

The study methods were approved by the Human Research Ethics Committee of the University of New
South Wales. A list of 814 specialist medical practitioners with practice addresses within the Sydney metropolitan region was supplied by the Medical Directory of Australia (AMPCo Pty Ltd). This included the major clinical subspecialties (listed in Table 1) with the exception of surgeons, who were not included because they have little responsibility for long-term prescribing. Of these, 400 specialists were randomly selected and a letter of invitation was sent which asked them to return a reply paid card if they were willing to be contacted further about the study. No reminders were sent to non-responders. The invitation letter outlined the study methods, requiring them to collect all materials received from pharmaceutical companies (excluding email correspondence) during a continuous eight-week period in late 2002. All participants were provided with labelled archive boxes (hereafter referred to as 'bins'). A member of the research team (Research Assistant) conducted all telephone and in-person interviews. During an introductory in-person interview, the project was discussed, and the support of an appropriate member of the specialist's staff (receptionist, or practice manager) was enlisted. Participants were contacted by telephone mid-way through the study to discuss progress. Bins were collected at the end of eight weeks and participants completed an exit

Table 1 Numbers of specialists included in the study.

\begin{tabular}{|c|c|}
\hline Specialists included and their specialties & Number \\
\hline Psychiatrists $^{\mathrm{a}}$ & 9 \\
\hline Paediatricians & 6 \\
\hline Oncologists $^{\mathrm{a}}$ & 4 \\
\hline Gastroenterologists $^{\mathrm{a}}$ & 4 \\
\hline Anaesthetists & 4 \\
\hline General physicians & 3 \\
\hline Renal physicians & 3 \\
\hline Immunologists & 3 \\
\hline Dermatologists & 3 \\
\hline Infectious disease physicians ${ }^{\mathrm{a}}$ & 2 \\
\hline Geriatricians & 2 \\
\hline Cardiologists $^{\mathrm{a}}$ & 2 \\
\hline Respiratory physicians $^{\mathrm{a}}$ & 2 \\
\hline Endocrinologist & 1 \\
\hline Intensive care physician & 1 \\
\hline Emergency medicine physician & 1 \\
\hline Reproductive medicine physician & 1 \\
\hline Total & 51 \\
\hline
\end{tabular}

${ }^{a}$ Member of a 'high value' prescribing specialty as per Pharmaceutical Benefits Scheme expenditure figures. 
interview in person or completed a questionnaire (if unavailable for an interview), which asked for an estimate of their success rate in depositing received items in the bin, whether there were other offers of gifts or items that were not captured, and their experience in conducting the study.

We analysed the data to determine whether gifts and drug samples were offered preferentially to members of 'high value' prescribing specialties, based on annual Pharmaceutical Benefits Scheme (PBS) reports of drug classes ranking by total cost to Government (during 2003) which define 'high value' prescribers as: psychiatrists; cardiologists; gastroenterologists; respiratory physicians; rheumatologists; infectious disease physicians; and oncologists. The associations between 'high value' prescribers and numbers of gifts (including number and type of drug samples) were quantified by odds ratios and $95 \%$ confidence intervals (calculated by the exact method) [16]. Bin collections were reviewed to see if any items breached the relevant sections of the Code of Conduct [1].

\section{Results}

\section{Response Rates}

One hundred and forty six medical specialists responded (response rate of 36.5\%) of whom 102 were willing to take part in the study $(25.5 \%)$. Of those: five did not meet the study criteria (two were not available during the study period, and three were not in active specialist medical practice). Of those who agreed to participate we selected 51 specialists, attempting to ensure representation of all relevant medical specialties.

\section{Respondent Characteristics}

Forty-two males and nine females participated, and all completed eight weeks of the study. The group comprised specialists from different specialties (see Table 1). On average, respondents divided their time equally between private and salaried practice (48 and $49 \%$, respectively). They spent $63 \%$ of their time in patient care, $15 \%$ in administration, $9 \%$ research, $7 \%$ teaching, and 6\% 'other'. Sixty-one percent of specialists saw $0-10$ patients per day, $31 \%$ saw $11-20,8 \%$ saw $21-30,2 \%$ saw more than 30 . Eight percent of specialists wrote no scripts, $76 \%$ prescribed 1-20 script items per day, $12 \% 21-50$ items, and $4 \%$ more than 50 . The mean number of pharmaceutical representatives seen during the eight-week study period was 7.4 (range 0-25). In both mid-point and exit interviews, participants reported that the study was relatively non-obtrusive and that the only difficulty was in remembering to put items in the designated 'bin'. In exit interviews participants estimated their success in depositing items, given or sent to them, in the 'bin' as between 80 and 100\% (mean 93\%).

\section{Bin Collections}

The study was conducted between mid-June and midDecember in 2002. The 51 respondents collected a total of 2,117 items (mean 41.5 items/participant; median 29; range 0-174) over eight weeks. Figure 1 shows the distribution of total numbers of items collected by participants and Fig. 2 displays the mean number of promotional/educational items, drug samples, office gifts, invitations, clinical practice aids, and personal gifts received.

\section{Details of Gifts}

Promotional/educational items $(n=1052$, mean $=20.6$ / participant) were received by 49 respondents (mean= 21.5, range 1-86). These included: promotional brochures (mean $=9.3$ participant), product information/consumer medicine information (mean $=3.6 /$ participant), and published paper reprints (mean $=2.4$ / participant). Some consisted of offers (mean $=2.4$ / participant), which on return of a card promised: drug samples (total $n=64$ ), textbook, CD-ROMs, access to websites for information (total $n=2$ ), sphygmomanometer, laser pointer, golf balls, clock, jar of sweets, jar of lollypops, and others. There were 'chance-towin' competitions (mean=1.0/participant) all of which required a response from the doctor, such as providing words to describe a drug, and offered prizes including: conference registration, flights and accommodation for a conference in USA; leather doctor's case (total $n=7$ ); pocket PC (total $n=6$ ); magazine subscription (total $n=4$ ); digital camera (total $n=3$ ); textbook (total $n=3$ ); and branded golf balls. Less common promotional items (mean $<1 /$ participant) included: sponsored newsletters, sponsored conference proceedings, journal issues, unpublished studies, 


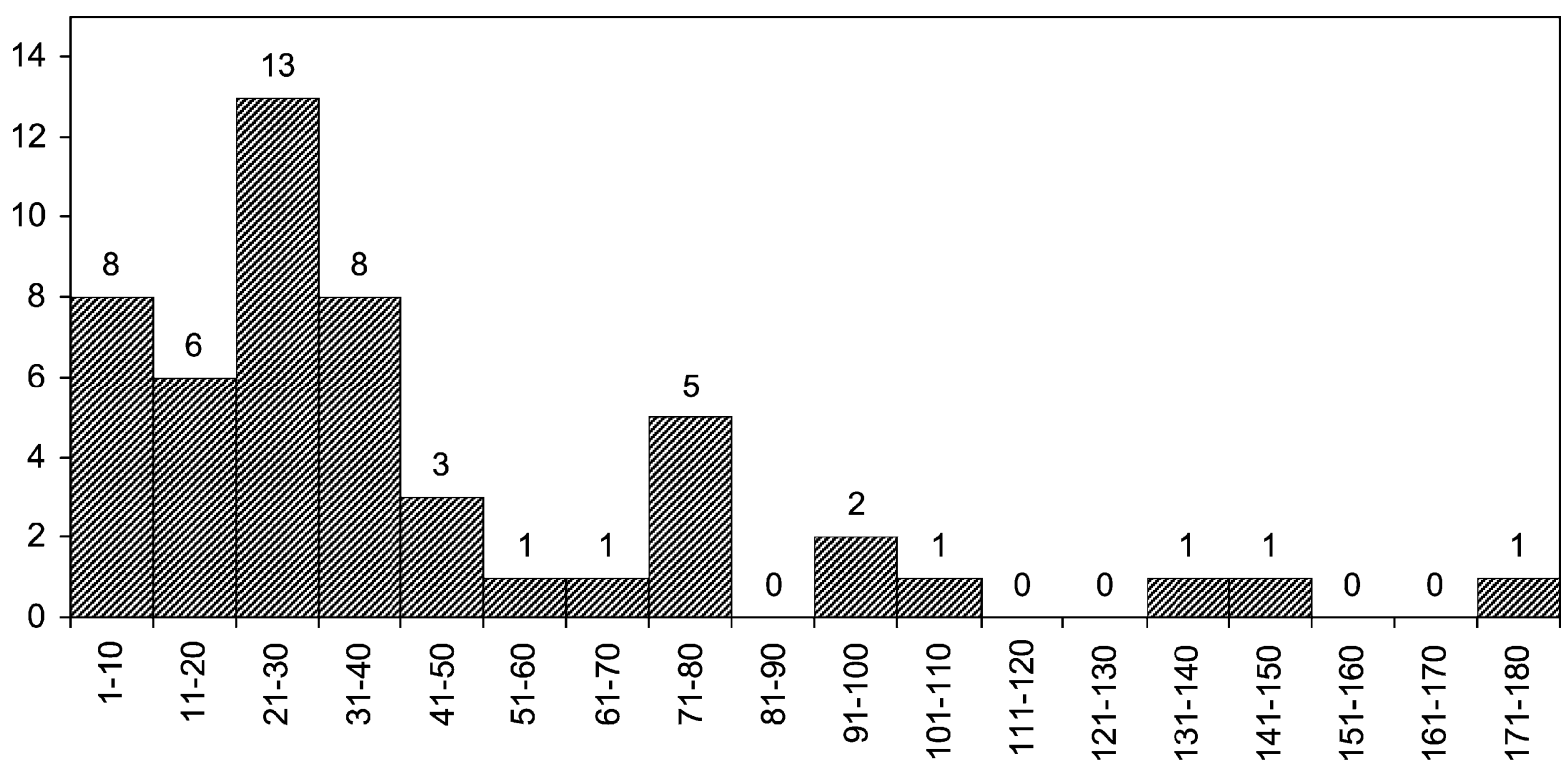

Number of items collected

Figure 1 Total numbers of items collected by participants.

audiotape/CDs, textbooks, published conference proceedings, sponsored practice guidelines and published practice guidelines.

Drug sample packs ( $n=420$ packs, mean $=8.2$ / participant) were received by 17 specialists (mean $=24.7$, range 1-104). Thirty-five percent of samples were drugs for gastrointestinal diseases (mainly acid pump inhibitors); $20 \%$ were drugs for psychiatric disorders (mainly anti-depressants); $19 \%$ were drugs for cardiovascular disorders (mainly angiotensin receptor antagonists); $14 \%$ were dermatological products; the remaining samples $(12 \%)$ were for musculoskeletal endocrine and allergic disorders. Of these sample packs 328 of 420 (78\%) were from the 'high value' drug classes (OR 4.7; $95 \%$ CI $2.5,9.0)$. Fewer than half of the participants (22 of 51, 43\%) came from 'high value' prescribing specialties (see above) but they were over-represented in the group that received drug samples during the study period (10 of 17) although the difference was not statistically significant (OR 2.6; 95\% CI 0.68, 10.3).

Office gifts ( $n=258$ items, mean=5.1/participant) were received by 34 specialists (mean $=7.6$, range $1-24$ ). These included pens (mean=2.1/participant) and the following items $\left(<1\right.$ item/participant): notepads, Post-it ${ }^{\odot}$ labels, mug, paper carry bag, fridge magnets, diary, laser pointers, cardholder. All were branded with the name of a drug (as was required) [1].
Invitations $(n=174$, mean $=3.2)$ were received by 36 specialists (mean $=4.8$, range $1-15$ ); with 89 dinner invitations received by 31 respondents (mean $=2.9$, range 1-9); and 48 invitations to breakfast received by 17 respondents (mean $=2.8$, range $1-10$ ). Dinner invitations included expensive restaurants (13 invitations to highest-rate $\$ \$ \$ \$$-category restaurants (http:// sydney.citysearch.com.au/section/food_wine/, last accessed August, 2005; http://www.eatability.com.au/, last accessed August, 2005) and 22 to restaurants in five-star hotels); many including entertainment (one such event being a recital by "Australia's most acclaimed classical pianist"). One dinner invitation included a competition with a travel grant to an international conference of the winner's choice. One participant received an invitation to an international conference with a business class airfare, accommodation, food, and registration (offered to the physician or member of his/her department). There were 13 invitations to weekend meetings with accommodation; most with travel, including: conferences/symposia/ educational $(n=9)$; events promoting a specific drug $(n=2)$; company advisory board $(n=1)$; and not specified $(n=1)$. Some invitations to weekend meetings included partner $(n=8)$ and some did not $(n=5)$. Of the eight invitations to weekend meetings that included partners and children $(n=4)$, all but one required 


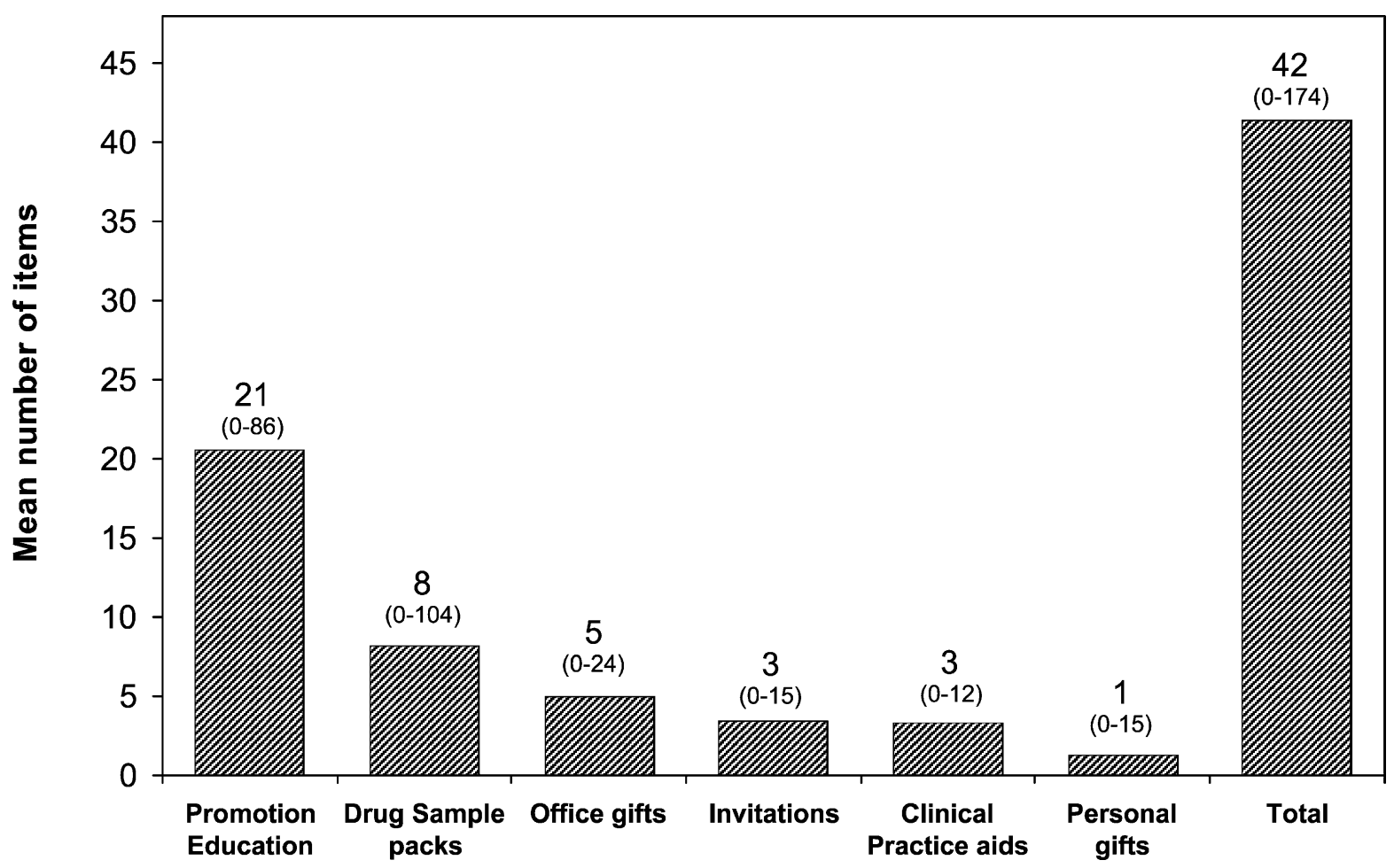

Figure 2 Mean number of items collected by participants according to category of item received.

contributions to the costs of partners (and children) in varying amounts for partner/child (\$100-245/partner and \$35-65/child). Two respondents received invitations to a 'post-graduate weekend' with accommodation, dinner and cabaret starring leading popular singer Tina Arena.

Clinical practice aids $(n=148$ items, mean $=2.9$ items/participant) were received by 29 specialists (mean $=5.1$, range $0-12$ ). These included: clinical equipment (stethoscope, sphygmomanometer, glucose test strips); patient/carer materials (mostly booklets); diagrams/models; and dose/drug interaction charts.

Personal gifts ( $n=65$ mean=1.3 items/participant) were received by 26 specialists $($ mean $=2.5$, range 0 15). These included many branded items $(n=55)$ such as: coffee plungers; shaving brushes; bottle openers; key rings with small flashlight; umbrellas; collapsible golf-putter set (including ball and wooden 'hole'); book on wines $(n=2)$; clocks; and red 'Viagra' boxer shorts. Unbranded personal gifts $(n=$ 10) included pocketknife; wine; chocolates; small tea chest; lamp; and tickets to a football (AFL) game with partner, including box seats, drinks and food; and two tickets to a cabaret.
There was no significant difference between the numbers of gifts received from the pharmaceutical industry by members of 'high value' prescribing specialties and others.

\section{Compliance with the Industry Code of Conduct}

We analysed the gifts received to consider which were in breach of the Code of Conduct of the Australian Pharmaceutical Manufacturers Association [1, the extant Code at the time of the study]. We took this Code as the benchmark, rather than the RACP guidelines [27], because pharmaceutical companies and their representatives are required to adhere to this Code; any breach of the Code can be the subject of a complaint which is investigated and reported on by a monitoring committee; and because breaches of this Code, unlike breaches of the Guidelines, could have led to direct sanctions [1].

We found that the following gifts breached the Code of Conduct [1]: tickets to entertainment events (including two tickets to the cabaret and two to an AFL football game) and dinner with entertainment by leading Australian performers. The Code stated, 
'[e]ntertainment or other hospitality offered to healthcare professionals should be appropriate, secondary to the educational content and in proportion to the occasion' [1]. A number $(n=33)$ of the 'chance-to-win' competitions included prizes that did not meet the requirement of being 'directly relevant to the practice of medicine or pharmacy' and of 'low monetary value.' These included: digital cameras; pocket PCs; and doctors' leather cases (which, although relevant to medicine, are expensive). However it is acknowledged that a doctors' leather case may now be permissible under supplementary guidelines to the subsequent Code, which allow competition prizes of a value up to $\$ 500$ [19]. The same Guidelines would also allow a pocket PC (or PDA) with MIMS or medical software [19]. Whilst the majority of personal gifts received by participants were consistent with the Code, some (such as a book on Australian wine) were of more than token value or were unbranded (e.g., soft toy, pocketknife). Two promotional documents, presented in the form of academic journal articles, proved on closer inspection to be company reports, in contravention of the Code [1].

Edition 14 of the Medicines Australia Code of Conduct [18] came into effect in January 2003 (subsequent to this study) with tighter restrictions including: provisions that companies should not pay the costs of family members of doctors attending meetings; provisions that ruled out entertainment; and further requirements that any hospitality offered should be simple, modest, and secondary to the educational content of a meeting [19]. The following offers received by participants in our study would have been excluded by the new rules: one night in 4.5 star hotel with partner wholly subsidised $(n=1)$; and invitations to dinner at expensive restaurants, five-star hotels, and restaurants where entertainment was provided $(n=35)$.

\section{Discussion}

A considerable volume and wide range of items, gifts, and invitations were received by medical specialists from the pharmaceutical industry over an eight-week period. The larger portion consisted of promotional/educational items, and drug samples. The drug samples offered were predominantly from 'high value' drug classes, indicating that companies are more active in promoting drugs with more profitable returns. Participants received 21 promotional/educational items on average. A few of these (up to four on average) may have been required by the Code (for example: product information was to accompany brochures promoting a 'new chemical entity' [1]) but even so this is a large number. Participants also received clinical aids, office gifts and invitations to dinner or breakfast associated with meetings. A small number received invitations to weekend meetings or events, some with their partners. Most gifts and invitations complied with the then current Code of Conduct. Those that breached the Code included invitations to entertainment or sporting events, items of high monetary value including 'chance-to-win' competitions with prizes of significant value, prizes unrelated to the practice of medicine, personal gifts of more than token value, and company promotional reports presented as academic journal articles. It is noted that offers of dinner at expensive restaurants, the provision of entertainment with dinner, and accommodation for a doctor's partner, whilst not specifically excluded by the then current Code [1], would have contravened the subsequent 2003 Code [18].

Some qualifications to these findings are as follows. A positive response rate of $25.5 \%$ from medical specialists is not unusual in a study that relies on posted responses to requests sent by mail. It is too low, however, to assume that our participants were representative of all Sydney-based medical specialists or the larger population of medical specialists throughout Australia. Given the geographical and other restraints on this study, achieving a more representative sample was not possible. Whilst we included at least one specialist from all the major specialties (other than surgery for reasons given above) the numbers were not sufficient within each group to make meaningful comparisons between the specialty groups. Nor are these results indicative of the number of gifts and other items received by general practitioners.

A further qualification is to do with the timing of the study. Some participants commented (during exit interviews) that fewer gifts and invitations had been offered in this period as a result of criticism of companies in the media at the time, and an expected tightening of the standards in the 2003 Code of Conduct [18]. It is also possible that not all gifts were 'captured,' although participants estimated that they had deposited between 80 and 100\% (average 93\%) of relevant items in the bins. 
Nevertheless, this is one of the few studies to date to publish observational data on the number of gifts and other items received by physicians from pharmaceutical companies. The number of gifts and other items received by our participants in a relatively brief (eight-week) collection period was considerable. Based on a direct extrapolation from these figures (to a 48 week year), a medical specialist, on average, could have then expected to receive around 230 items, comprising 125 promotional/educational items (including 14 offers of gifts and six competitions on return of a card); 50 drug sample packs; 30 office gifts; 20 invitations (including 11 invitations to dinner and one weekend meeting at a four or five star hotel); 17 clinical practice aids; and eight personal gifts.

These findings give some indication of the extent to which the industry Code was effective in maintaining limits on the giving of gifts to medical practitioners. By and large, most gifts were within the required limits, although there were significant breaches. Since 2002, the Code has been amended (in 2003 [18] and in 2006 [20]). It may be reasonable to assume that most gifts, invitations, and items offered to medical practitioners will conform to the stricter limitations in the current Code. However it can be expected that, without evidence of any other significant change in the industry, company representatives will continue to test the limits and some will go beyond them. It can also be anticipated that, with stricter limits, companies will become more inventive in finding alternative means for promotion. There are already indications that pharmaceutical companies have shifted their promotional efforts. They now give greater emphasis to indirect promotion by funding continuing medical education for medical practitioners [2].

The broader context of this study is that professional bodies and pharmaceutical companies have responded to accusations of professional or commercial impropriety by developing codes of ethics to govern the relationship between industry and the profession in order to restore and maintain public confidence. Competition within the pharmaceutical industry for market share is the principal driver for promotional activity including the giving of gifts in addition to other items. The aim of pharmaceutical companies is to influence doctors' prescribing behaviour and gain a competitive advantage. The result of these activities was that pharmaceutical company largesse became the norm. This led to a culture in which gifts were offered because they were expected, accepted, and desired by medical practitioners. In that environment, ethical limits were stretched and, in some cases, breached. We note however that the most recent industry Code [20] and professional Guidelines [28] are more restrictive in regards to what gifts and sponsorship companies can offer, and more conservative in the recommendations to physicians as to what they can appropriately receive. These documents may aid in bringing about a change in the culture.

This study is part of a larger project that aims to establish whether the relationship between the pharmaceutical industry, the medical profession, and medical practitioners is appropriate in terms of justifiable ethical standards, empirical research and social perspectives. The aspect of the relationship focussed on in this study is the giving of gifts and other items. We take the view that, while some items given may be judged to be appropriate, there were many that are difficult to justify.

We are persuaded by Katz et al., that gifts, including those of negligible value, can influence the behaviour of doctors and that policies that determine the acceptability of a gift according to its size are unsound' [12]. We also note that the Medicines Australia Code now limits gifts to 'brand name reminders' of 'token value' that are 'relevant to the working environment' [20]. However these provisions do not take sufficient account of the 'power of gift-giving, both large and small' on medical practitioners. Katz et al. take the view that gifts are 'marketing wares' and that 'all gifts, large and small,' are not appropriate and should be prohibited [12]. The RACP Guidelines [28] observe that 'even items of small value which superficially appear to be innocuous are intended to sway doctors' judgments' and may create an impression at least that the doctor has not kept an appropriate distance from the industry. The Guidelines recommend that all gifts including 'items of trivial value such as pens or message pads' be rejected [28]. We support that recommendation and suggest that the RACP standard should be adopted by the industry so that companies refrain from giving gifts of all kinds, including those given as brand name reminders and gifts given as the result of a "competition."

We found that physicians receive a great deal of promotional material. Whilst we accept the concern of the RACP that this material can be biased, incomplete, 
and unsupported by evidence [28], we agree that it is unrealistic to prohibit its use [15]. We therefore support both the Medicines Australia approach of requiring that this material meet certain standards [20], and the RACP strategy of encouraging doctors to critically evaluate all promotional material [28].

Drug sample packs were received by a large number of the participants in our study. Since this study was conducted both the industry Code [20] and the professional Guidelines [28] have become more cautious with regard to drug samples. The Medicines Australia Code now requires that doctors make a written request for drug samples [20] while the RACP Guidelines state that it is 'usually inappropriate' to accept drug samples because the purpose for giving samples is to 'accustom the clinician to prescribing a particular product' and 'to establish a cohort of patients on long-term treatment with a particular drug' $[9,28]$. The drugs most commonly given to physicians in our sample were from 'high value' drug classes. This supports a view, expressed by Grove et al., that drug samples are a 'major component of the promotional effort' and a 'critical driver in the promotion and adoption of new products' [9]. Many concerns have been expressed about potential negative effects of drug samples including: influencing prescriber behaviour; patient safety; and adding to the cost to of pharmaceuticals [9]. Grove et al. conclude that research into these effects is lacking and is needed to underpin policies on the use of drug samples [9]. Nevertheless we take the view that the potential for bias and for harm to patients, and an apparent upward pressure on the cost of drugs, are consequences that are sufficiently serious to justify taking a conservative approach. We therefore support the RACP recommendation that doctors should not accept drug samples 'apart from exceptional circumstances' [28] and suggest that further reflection is required to define the 'exceptional circumstances' in which the acceptance of drug samples might be appropriate so that the giving of drug samples can be restricted to just those circumstances. A similar approach has been proposed by the RACP in relation to practice aids, whereby gifts of 'service-oriented items' are only appropriate where they 'are not otherwise readily available' [28].

There was one offer of business class international travel received from a pharmaceutical company by a physician in our study. In our view this is an inappropriate gift unless it is received indirectly from the organisers of a conference or meeting and we support the RACP restrictions on travel and attendance costs for attending meetings [28, 17]. Many of our study participants received invitations to meals paid for by pharmaceutical companies in association with meetings or educational events. We suggest that caution is needed in giving and receiving of food and hospitality. We note that both the current industry Code [20] and RACP Guidelines [28] allow hospitality in conjunction with a meeting (when there is a significant educational content) provided it is not extravagant [20] or lavish [28]. We found that there were at least 37 meals offered in restaurants with the top ratings or fivestar hotels. Given that individuals judge standards according to their own values we suggest that it could always be argued that such offerings were not extravagant or lavish and were 'consistent with the professional standing' [20] of the physicians. We suggest that this language is too permissive and recommend to the RACP and Medicines Australia that they re-consider those provisions and use the language of the previous industry Code that restricted hospitality to meals that are 'simple' and 'modest' [18].

We take heart from the fact that the pharmaceutical industry body (Medicines Australia) and a predominant specialist college (RACP) are active in reviewing the relationship between the pharmaceutical industry, the medical profession, and medical practitioners and that both bodies appear to be alert to community concerns, empirical research, and social perspectives on the appropriateness of gifts and items given by pharmaceutical companies and received by medical practitioners.

Acknowledgements This study was supported by a grant from the National Health and Medical Research Council of Australia. The authors and research team were completely independent of the funders in the conduct and write up of this study. We are extremely grateful to the medical specialists who took part in the collection of gifts from pharmaceutical companies. We also thank the anonymous reviewers of an earlier version of this paper.

\section{References}

1. Australian Pharmaceutical Manufacturers' Association (2000). Edition 13 Code of Conduct of the Australian Pharmaceutical Manufacturers' Association, 1999 December (effective 1 January 2000) with amendments (adopted September 2000). Deakin, ACT, Australia: Medicines Australia.

2. Blumenthal, D. (2004). Doctors and drug companies. 
New England Journal of Medicine, 351(18), 1885-1890, October 28.

3. Brody, H. (2005). The company we keep: Why physicians should refuse to see pharmaceutical representatives. Annals of Family Medicine, 3(1), 82-85, January 1.

4. Caamano, F., Figueiras, A., \& Gestal-Otero, J. J. (2002). Influence of comercial information on prescription quantity in primary care. European Journal of Public Health, 12, 187-191.

5. Collier, J., \& Iheanacho, I. (2002). The pharmaceutical industry as informant. Lancet, 360, 1405-1409.

6. Doran, E., Kerridge, I. K., McNeill, P. M., \& Henry, D. A. (2005). Empirical uncertainty and moral contest: A qualitative analysis of the relationship between medical specialists and the pharmaceutical industry in Australia. Social Science \& Medicine, 62(6), 1510-1519, March 2006.

7. Gibbons, R. V., Landry, F. J., Blouch, D. L., Jones, D. L., Williams, F. K., Lucey, C. R., et al. (1998). A comparison of physicians' and patients' attitudes toward pharmaceutical industry gifts. Journal of General Internal Medicine, 13, 151-154.

8. Griffith, D. (1999). Reasons for not seeing drug representatives. British Medical Journal, 319(7202), 69-70, July 10.

9. Groves, K. E., Sketris, I., \& Tett, S. E. (2003). Prescription drug samples - Does this marketing strategy counteract policies for quality use of medicines? Journal of Clinical Pharmacy and Therapeutics, 28(4), 259-271.

10. Henry, D. A., Doran, E., Kerridge, I. H., Hill, S. R., McNeill, P. M., \& Day, R. O. (2005). Ties that bind: Multiple relationships between clinical researchers and the pharmaceutical industry. Archives of Internal Medicine, 165, 2493-2496, November 28.

11. Henry, D. A., Kerridge, I. H., Hill, S. R., McNeill, P. M., Doran, E., Newby, D. A., et al. (2005). Medical specialists and pharmaceutical industry-sponsored research: A survey of Australian experience. Medical Journal of Australia, 182 (11), 557-560.

12. Katz, D., Caplan, A. L., \& Merz, J. F. (2003). All gifts large and small: Toward an understanding of the ethics of pharmaceutical industry gift giving. American Journal of Bioethics, 3(3), 39-46.

13. Kerridge, I. H., Maguire, J., Newby, D. A., McNeill, P. M., Henry, D., Hill, S., et al. (2005). Cooperative partnerships or conflict-of-interest? A national survey of interaction between the pharmaceutical industry and medical organizations. Internal Medicine Journal, 35(4), 206-210.

14. Komesaroff, P. A. (2005). Ethical issues in the relationship with industry: An ongoing challenge. New guidelines open for public comment. Journal of Paediatrics Child Health, 41, 558-560.

15. Mansfield, P. R. (2005). Banning all drug promotion is the best option pending major reforms. Journal of Bioethical Inquiry, 2(2), 75-81.

16. Martin, D. O., \& Austin, H. (1991). An efficient program for computing conditional maximum likelihood estimates and exact confidence limits for a common odds ratio. Epidemiology, 2(5), 359-362, (Sep).

17. McNeill P. M., Kerridge I. H., Henry D. A., Stokes B., Hill S. R., Newby D., et al. The giving and receiving of gifts between pharmaceutical companies and medical specialists in Australia. Internal Medicine Journal, 36(9), 571-578.

18. Medicines Australia, Code of Conduct, Edition 14, January 2003.

19. Medicines Australia, Code of Conduct, Edition 14, Guidelines, Version 3 (effective 24 September 2004). Deakin, ACT, Australia: Medicines Australia.

20. Medicines Australia, Code of Conduct, Edition 15, given interim authorisation April 2006. Final authorisation expected June 2006. From correspondence with Medicines Australia.

21. Moynihan, R. (2003). Who pays for the pizza? Redefining the relationships between doctors and drug companies. 1: Entanglement. British Medical Journal, 326(7400), 1189-1192.

22. Robertson, J., Fryer, J. L., O'Connell, D. L., Sprogis, A., \& Henry, D. A. (2001). The impact of specialists on prescribing by general practitioners. Medical Journal of Australia, 175(8), 407-411, Oct 15.

23. Smith, R. (2003). Medical journals and pharmaceutical companies: Uneasy bedfellows. British Medical Journal, 326, 1202-1205.

24. Steinman, M. A., Shlipak, M. G., \& McPhee, S. J. (2001). Of principles and pens: Attitudes and practices of medical house staff toward pharmaceutical industry promotions. American Journal of Medicine, 10(7), 551-557.

25. Stryer, D., \& Bero, L. A. (1996). Characteristics of materials distributed by drug companies. An evaluation of appropriateness. Journal of General Internal Medicine, 11 (10), 575-583, Oct.

26. The Australian Medical Association. Doctors' relationships with the pharmaceutical industry (2002). http://www.ama.com. au/web.nsf/doc/WEEN-5GJ7MH (last accessed May 2006).

27. The Royal Australasian College of Physicians (1999). Ethical guidelines in the relationship between physicians and the pharmaceutical industry (2nd ed.). Sydney: The Royal Australasian College of Physicians.

28. The Royal Australasian College of Physicians (2006). Guidelines for ethical relationships between physicians and industry (3rd ed.). Sydney: The Royal Australasian College of Physicians (May).

29. Watkins, C., Moore, L., Harrvey, I., \& Carthy, P. (2003). Characteristics of general practitioners who frequently see drug company representatives: National cross sectional study. British Medical Journal, 326, 1178-1179.

30. Wazana, A. (2000). Physicians and the Pharmaceutical industry: is a gift ever just a gift. Journal of the American Medical Association, 283(3), 373-380.

31. Wazana, A., Granich, A., Primeau, F., Bhanji, N. H., \& Jalbert, M. (2004). Using the literature in developing McGill's guidelines for interactions between residents and the pharmaceutical industry. Academic Medicine, 79(11), 1033-1040 (Nov 1). 